\title{
Cerrahpasa Experience in Topical Immunotherapy Treatment in Patients with Alopecia Areata, Totalis and Universalis
}

\author{
(1) Özge Așkın¹, (1) Ayșe Mine Gök ${ }^{1}$, (1) Server Serdaroğlu¹, (1) Beril Kara² \\ ${ }^{1}$ Istanbul University-Cerrahpasa, Cerrahpasa Faculty of Medicine, Department of Dermatology and Venereology, Istanbul, Turkey \\ IIstanbul University-Cerrahpasa, Cerrahpasa Faculty of Medicine, Department of Public Health, Istanbul, Turkey
}

\section{ABSTRACT}

Background: Alopecia areata is a common hair problem and affects patients psychologically. Although the disease has a wide range of treatments, the responses are variable.

Materials and Methods: We retrospectively analyzed the data of 213 patients who received topical immunotherapy treatment in our clinic between 2014 and 2019.

Results: There was no significant difference in response rates in the two treatment types in women $(p=0.120)$. The total response rate of the patients treated with squaric acid dibutyl ester (SADBE) was 42.9\% (30/70) and the total response rate of the patients treated with diphenylcyclopropenone (DPCP) was significantly higher than 19.2\% (10/52) ( $p=0.023)$. The mean age (9.73 years) of those who received full response from SADBE treatment was significantly lower than the mean age (12.65 year) of those who received full response from DPCP treatment $(p=0.003)$. In all response cases, there was no significant difference between both treatment types and disease duration. Considering all the data, 1 month increase in the disease duration caused $1 \%$ worse response to the treatment $($ Wald $=8.97, p=0.003)$. Considering all the data, 1 month increase in the treatment period caused $1.04 \%$ better response to the treatment (Wald=9.79, $p=0.002)$. Those with a pre-treatment loss of less than $25 \%$ were found to be 7.5 times better than those with a pre-treatment loss of $100 \%$ (Wald $=19.37$ $p<0.001)$. Considering all the data, the patients who received SADBE treatment received 2 times better response to treatment than those who received DPCP treatment (Wald $=8.875, p=0.003$ ).

Conclusion: In conclusion, we think that topical immunotherapy is an important form of treatment in alopecia areata and more studies are needed.

Keywords: Alopecia areata, Alopecia totalis, Alopecia universalis, Immunotherapy

\section{Introduction}

Alopecia areata is characterized by acute-onset, sharply limited alopecic plaques [1]. In severely affected individuals, alopecia areata can progress to include all scalp hair (alopecia totalis) or all scalp and body hair (alopecia universalis) [2]. Alopecia areata affects approximately $2 \%$ of the population [3]. Among the US population, the cumulative lifetime incidence of alopecia areata is estimated at $2 \%$ [4]. The pathomechanism remains unknown [5]. The management of alopecia areata involves both addressing the psychologic needs of the patient and offering treatment to patients who desire intervention. A variety of topical, intralesional, and systemic agents, as well as devices, have been used for alopecia areata, but the response to treatment varies widely. Topical immunotherapy is probably the most effective treatment for patients with extensive or recurrent scalp 
involvement [6,7]. A potent contact allergen is applied weekly to the scalp to precipitate hair regrowth $[8,9]$. The reason for this response remains unknown, but an immunomodulatory effect on the inflammatory infiltrate surrounding affected hair follicles is thought to play a role. Theories for the mechanism of action have focused on the inhibition of the pathologic immune response via antigenic competition [10] the induction of lymphocyte apoptosis [11], or an effect on the type or function of lymphocytes in the inflammatory infiltrate $[12,13,14]$.

\section{Materials and Methods}

In our study, we aimed to investigate the effectiveness of topical immunotherapy agents used in the treatment of patients with alopecia areata, totalis, and universalis, or the factors affecting the response received with these treatment methods. We analyzed the data of patients with alopecia areata, totalis and universalis who received topical immunotherapy between 20142019 retrospectively. We examined the data of a total of 213 patients. All patients' age, gender, disease duration, duration of treatment, percentage of hair loss before and after treatment, presence of nail involvement, and type of treatment findings were recorded.

\section{Statistical Analysis}

Statistical analysis part was done using SPSS version 21. Normalities of continuous variables were evaluated with Kolmogorov-Smirnov and Q-Q plots. Binary comparisons were made by using the chisquare in categorical variables and Fisher's exact test according to the location, and the t-test in independent groups and the Mann-Whitney $U$ test according to their normalities in continuous variables. Relationship in multi-eyed categorical variables was examined using Cramer's V test. During the examination of the treatment response with univariate analyzes, the chi-square test was used. Spearman correlation test was used to determine the variables that were correlated in continuous variables. In the multivariate analysis, independent predictors in predicting the outcome of the treatment using possible factors identified in previous analyzes were examined using ordinal regression analysis. Necessary tests were examined for model fit. P value under 0.05 was considered significant.

\section{Results}

We examined the data of a total of 213 patients. Of these 213 patients, 91 were male and 122 were female. The median age of the patients was 10.9 years. The mean disease duration of the patients was 3.6 years. The mean treatment period of the patients was 1.38 years. We detected the loss of pre-treatment (40.8\% of the patients) as the 100\% hair loss. Of 213 patients, 117
(54.9\%) had nail changes prior to treatment. Out of 213 patients, 125 were treated with squaric acid dibutyl ester (SADBE) and 88 were treated with diphenylcyclopropenone (DPCP). There was no significant difference in response rates in the two treatment types in women $(p=0.120)$. The total response rate of the patients treated with SADBE was $42.9 \%$ (30/70) and the total response rate of the patients treated with DPCP was significantly higher than $19.2 \%(10 / 52)(p=0.023)$. The mean age (9.73 years) of those who received full response from SADBE treatment was significantly lower than the mean age (12.65 year) of those who received full response from DPCP treatment $(p=0.003)$. In all response cases, there was no significant difference between both treatment types and disease duration. Considering all the data, 1 month increase in the disease duration caused $1 \%$ worse response to the treatment (Wald $=8.97, p=0.003)$. Considering all the data, 1 month increase in the treatment period caused $1.04 \%$ better response to the treatment (Wald $=9.79, p=0.002$ ). Those with a pre-treatment loss of less than $25 \%$ were found to be 7.5 times better than those with a pre-treatment loss of 100\% (Wald=19.37, $p<0.001$ ). Considering all the data, the patients who received SADBE treatment received 2 times better response to treatment than those who received DPCP treatment (Wald $=8.875, p=0.003$ ) (Figure 1, 2, 3, and 4).

\section{Discussion}

The purpose of treatment in alopecia areata involves both addressing the psychological needs of the patient and offering treatment to patients seeking intervention. In our clinic, we apply
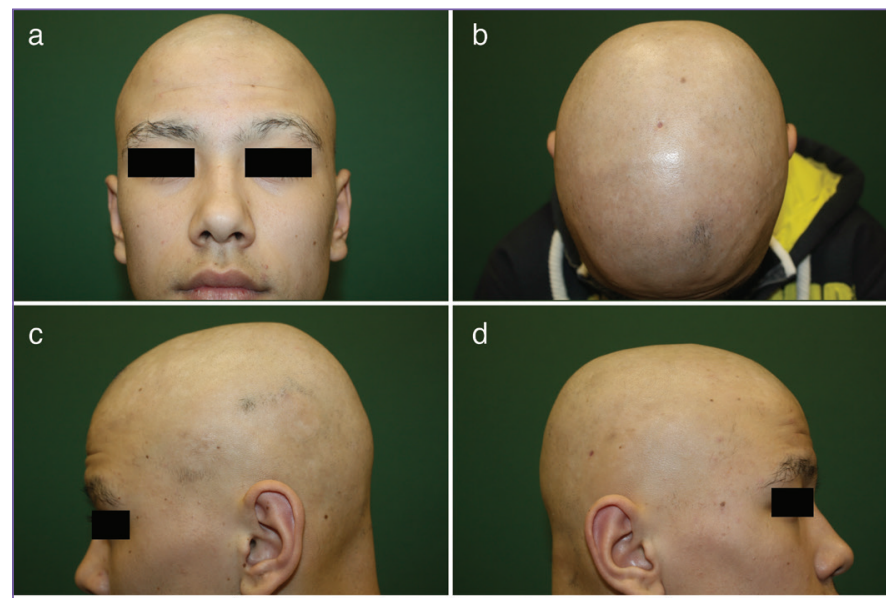

d

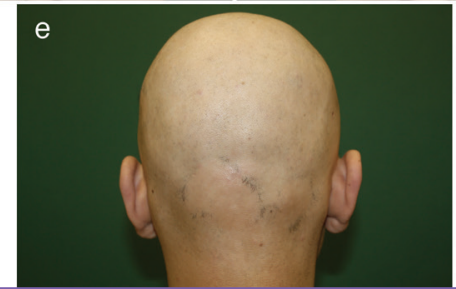

Figure 1. Before the squaric acid dibutyl ester treatment 
topical immunotherapy for patients who need treatment and who have extensive or recurrent scalp involvement.

Randomized trials evaluating topical immunotherapy are lacking, and uncontrolled studies have found variable rates of response. A systematic review and meta-analysis of studies evaluating contact
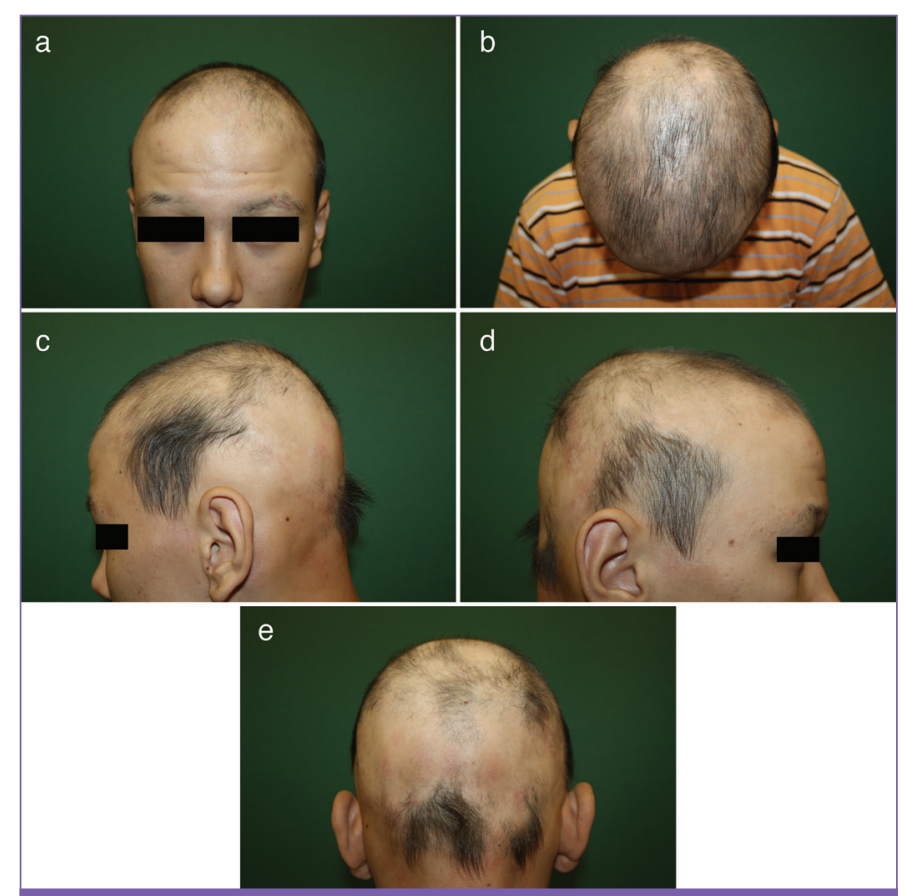

Figure 2. Fifth month in the squaric acid dibutyl ester treatment
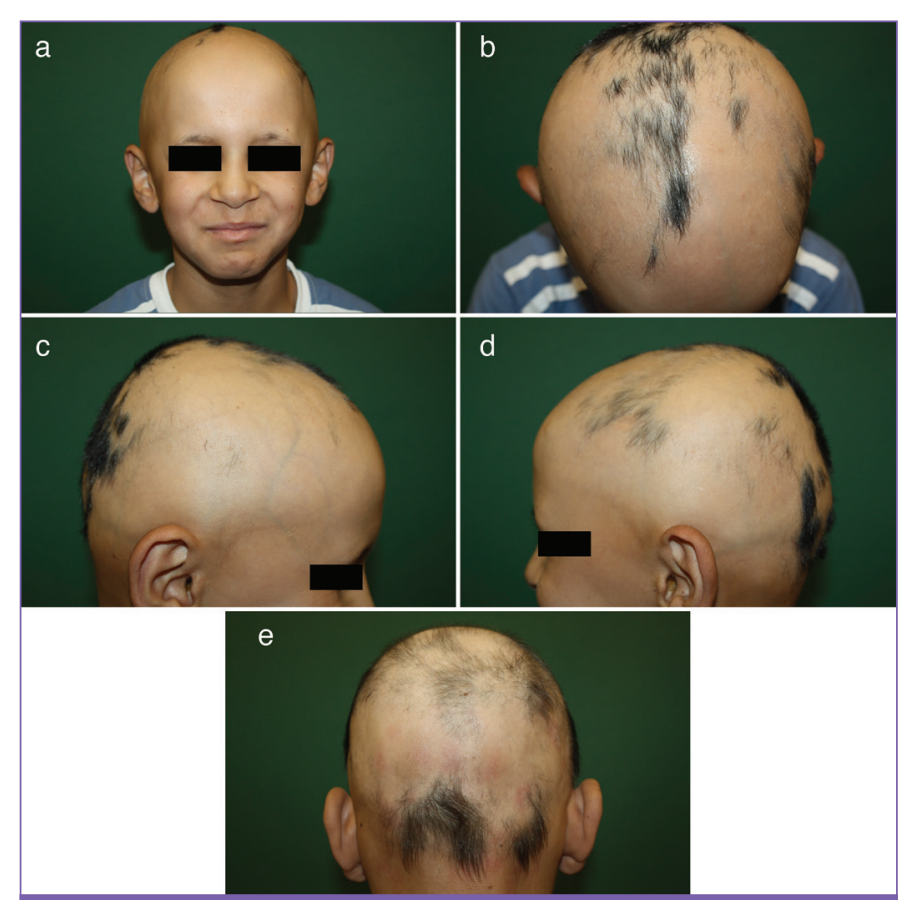

Figure 3. Before the diphenylcyclopropenone treatment
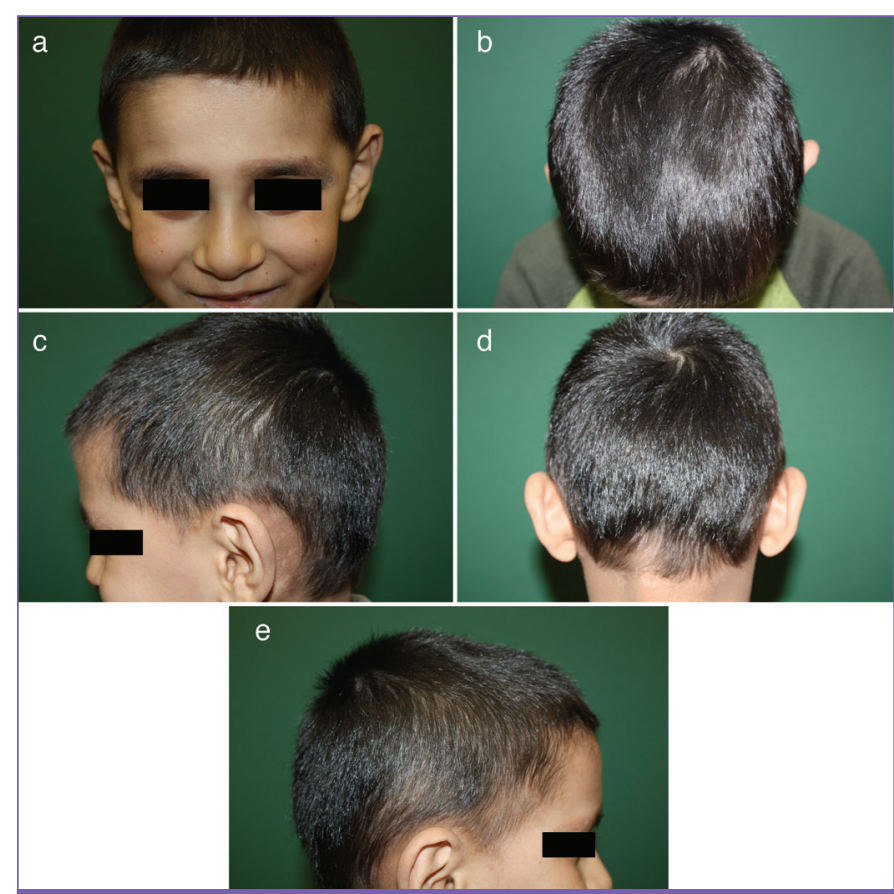

Figure 4. Sixth month in the diphenylcyclopropenone treatment

immunotherapy with DPCP or SADBE for patchy alopecia areata, alopecia totalis, and/or alopecia universalis found an overall rate of complete (90 to 100 percent) hair regrowth of 32.3 percent [95\% confidence interval (CI): 25.3-40.2]. Patients with patchy alopecia areata had better response rates than patients with either alopecia totalis or universalis (25 versus 43 percent for complete regrowth). Factors associated with poorer hair regrowth outcomes included a Severity of Alopecia Tool score $\geq 50$ [odds ratio (OR): 3.05, 95\% Cl: 2.26-4.11], atopic disease (OR: 1.61, 95\% Cl: 1.03-2.50), and nail involvement (OR: 2.06, 95\% Cl: 1.26-3.36). Although longer disease duration is often considered a negative prognostic factor, disease duration $\geq 1$ year was not a statistically significant prognostic factor in this study (OR: 1.56, 95\% Cl: 0.95-2.55). Relapse after treatment was common. Analysis of studies reporting treatment status at the time of relapse revealed recurrence rates among patients not receiving and receiving maintenance treatment of 38 and 49 percent, respectively [15].

\section{Conclusion}

In our study, we found that those who had a pre-treatment loss of less than $25 \%$ received a better response from treatment were 7.5 times better than those with a pre-treatment loss of $100 \%$. This data was compatible with the above mentioned metaanalysis. In contrast to the above metaanalysis, considering all the data in our study, 1-month increase in disease duration caused $1 \%$ worse response to treatment (Wald $=8.97, p=0.003)$. 
There are few studies comparing two topical immunotherapy in the literature. Our study contributes to the literature in this respect and reflects the Cerrahpasa experience. Further studies are needed in this treatment arm.

\section{Ethics}

Ethics Committee Approval: The study were approved by the Istanbul University-Cerrahpasa, Cerrahpasa Faculty of Medicine of Local Ethics Committee (decision number: 216, date: 21.06.2022).

Informed Consent: Not received.

Peer-review: Internally peer-reviewed.

\section{Authorship Contributions}

Surgical and Medical Practices: Ö.A., A.M.G., S.S., B.K., Concept: Ö.A., A.M.G., S.S., B.K., Design: Ö.A., A.M.G., S.S., B.K., Data Collection or Processing: Ö.A., A.M.G., S.S., B.K., Analysis or Interpretation: Ö.A., A.M.G., S.S., B.K., Literature Search: Ö.A., A.M.G., S.S., B.K., Writing: Ö.A., A.M.G., S.S., B.K.

Conflict of Interest: No conflict of interest was declared by the authors.

Financial Disclosure: The authors declared that this study received no financial support.

\section{References}

1. Trüeb RM, Dias MFRG. Alopecia Areata: a Comprehensive Review of Pathogenesis and Management. Clin Rev Allergy Immunol 2018;54:68-87.

2. Finner AM. Alopecia areata: Clinical presentation, diagnosis, and unusual cases. Dermatol Ther 2011;24:348-354.

3. Gupta AK, Carviel JL, Foley KA, Shear NH, Piraccini BM, Piguet V, Tosti A. Monotherapy for Alopecia Areata: A Systematic Review and Network MetaAnalysis. Skin Appendage Disord 2019;5:331-337.
4. Strazulla LC, Wang EHC, Avila L, Lo Sicco K, Brinster N, Christiano AM, Shapiro J. Alopecia areata: Disease characteristics, clinical evaluation, and new perspectives on pathogenesis. J Am Acad Dermatol 2018;78:1-12.

5. Dainichi T, Kabashima K. Alopecia areata: What's new in epidemiology, pathogenesis, diagnosis, and therapeutic options? J Dermatol Sci 2017;86:312.

6. Messenger AG, McKillop J, Farrant P, McDonagh AJ, Sladden M. British Association of Dermatologists' guidelines for the management of alopecia areata 2012. Br J Dermatol 2012;166:916-926.

7. Ro BI. Alopecia areata in Korea (1982-1994). J Dermatol 1995;22:858-864.

8. Rokhsar CK, Shupack JL, Vafai JJ, Washenik K. Efficacy of topical sensitizers in the treatment of alopecia areata. J Am Acad Dermatol 1998;39:751-761.

9. van der Steen PH, van Baar HM, Perret CM, Happle R. Treatment of alopecia areata with diphenylcyclopropenone. J Am Acad Dermatol 1991;24:253-257.

10. Happle R. Antigenic competition as a therapeutic concept for alopecia areata. Arch Dermatol Res 1980;267:109-114.

11. Herbst V, Zöller M, Kissling S, Wenzel E, Stutz N, Freyschmidt-Paul P. Diphenylcyclopropenone treatment of alopecia areata induces apoptosis of perifollicular lymphocytes. Eur J Dermatol 2006;16:537-542.

12. Happle R, Klein HM, Macher E. Topical immunotherapy changes the composition of the peribulbar infiltrate in alopecia areata. Arch Dermatol Res 1986;278:214-218.

13. Wasyłyszyn T, Kozłowski W, Zabielski SL. Changes in distribution pattern of CD8 lymphocytes in the scalp in alopecia areata during treatment with diphencyprone. Arch Dermatol Res 2007;299:231-237.

14. Hoffmann R, Wenzel E, Huth A, van der Steen P, Schäufele M, Henninger HP, Happle R. Cytokine mRNA levels in Alopecia areata before and after treatment with the contact allergen diphenylcyclopropenone. J Invest Dermatol 1994;103:530-533.

15. Lee S, Kim BJ, Lee YB, Lee WS. Hair Regrowth Outcomes of Contact Immunotherapy for Patients With Alopecia Areata: A Systematic Review and Meta-analysis. JAMA Dermatol 2018;154:1145-1151. 